\title{
Propentofylline decreases hypothalamic astrogliosis induced by hypercaloric diet in the rat
}

\author{
A propentofilina diminui a astrogliose hipotalâmica induzida pela dieta hipercalórica \\ no rato
}

\author{
Eduardo Fernandes Bondan 1,2, Carolina Cardoso Vieira1, Maria de Fátima Monteiro Martins ${ }^{1,2}$, Thiago Berti \\ Kirsten', Maria Martha Bernardi1
}

\begin{abstract}
Obesity is associated with a chronic and low-grade inflammatory response in the hypothalamus, where astrogliosis occurs with the upregulation of the astrocyte structural protein GFAP. As propentofylline (PPF) has inhibitory effects on astrocyte and microglial activation during inflammation, this study aimed to investigate if this xanthine derivative could decrease the astrocyte reaction induced by a hypercaloric diet (HD). Male Wistar rats were divided into four groups: NDS - rats receiving a normocaloric diet (ND) and daily saline solution; NDP - rats receiving ND and daily PPF $(12.5 \mathrm{mg} / \mathrm{kg} /$ day, intraperitoneal route); HDS - rats receiving HD and saline solution, HDP - rats receiving HD and PPF. On the $21^{\text {st }}$ day, rats were anesthetized, and perfused, and brains were collected for GFAP immunohistochemical study in the hypothalamus. Results showed that HD induced increased weight gain and hypothalamic astrogliosis. Propentofylline decreased the expression of GFAP in the HDP group, although it did not affect the weight gain induced by this diet.
\end{abstract}

Keywords: astrocytes; central nervous system; inflammation; obesity; xanthine.

\section{RESUMO}

A obesidade está associada com uma resposta inflamatória crônica e de baixo grau no hipotálamo, onde ocorre astrogliose com a superexpressão da proteína astrocitária GFAP. Como a propentofilina (PPF) possui efeitos inibitórios sobre a ativação astrocitária e microglial durante a inflamação, este estudo visou a investigar se esta xantina podia diminuir a reação astrocitária induzida pela dieta hipercalórica (HD). Ratos Wistar machos foram divididos em 4 grupos: NDS- ratos recebendo dieta normocalórica (ND) e solução salina diária; NDPratos recebendo ND e PPF diária (12.5 mg/kg/dia, via intraperitoneal); HDS- ratos recebendo HD e solução salina, HDP- ratos recebendo HD e PPF. No $21^{\circ} \mathrm{dia}$, os ratos foram perfundidos e os encéfalos, coletados para estudo imuno-histoquímico para a GFAP no hipotálamo. Os resultados mostram que a HD induziu aumento do ganho de peso e astrogliose no hipotálamo. A PPF diminuiu a expressão de GFAP no grupo HD, embora não tenha afetado o ganho de peso induzido por esta dieta.

Palavras-chave: astrócitos; sistema nervoso central; inflamação; obesidade; xantina.

The concept that obesity could affect the central nervous system (CNS), specifically the brain, has recently emerged ${ }^{1}$. Cognitive abnormalities, specifically learning and memory deficits, have been reported in obesity and typical comorbid disorders $^{1,2}$. There are several associations between obesity and neurological disorders, including sleep apnea, anxiety, manic depressive disorders and increased risk of having a cerebrovascular accident ${ }^{3}$. It also has been reported that obesity is associated with changes in volume or density of gray and white matter, assessed by magnetic resonance imaging ${ }^{4,5}$. Obesity-associated structural abnormalities in the brain ${ }^{5}$ contribute to a higher incidence of diseases, such as dementia ${ }^{6}$ and Alzheimer's disease $^{7}$. Although the exact cause remains unknown, it has been assumed that CNS disorders are triggered by multifactorial events including neuroinflammation and oxidative stress ${ }^{8}$. Neuroinflammation leads to resident glial cells (astrocytes and microglia) activation, which results in invasion of circulating immune cells and production of proinflammatory cytokines, such as tumor necrosis factor- $\alpha$ (TNF- $\alpha$ ), interleukin (IL)- $1 \beta$, and IL-6, and reactive oxygen species ${ }^{8}$.

Therefore, obesity is characterized by chronic and low-grade inflammation in several tissues, including the $\mathrm{CNS}$, and particularly the hypothalamus, which is known to regulate food intake and energy expenditure ${ }^{9,10}$. The arcuate and the paraventricular nuclei are two key hypothalamic areas of this central network and play a critical role in maintenance of energy balance ${ }^{11}$.

${ }^{1}$ Universidade Paulista, Patologia Ambiental e Experimental, São Paulo SP, Brasil;

2 Universidade Cruzeiro do Sul, Medicina Veterinária, São Paulo SP, Brasil.

Correspondence: Eduardo Fernandes Bondan; Rua Caconde, 125 / 51; 01425-011 São Paulo SP, Brasil; E-mail: bondan@uol.com.br

Conflict of interest: There is no conflict of interest to declare.

Received 27 November 2017; Received in final form 04 January 2018; Accepted 13 January 2018. 
Astrocytes are known to be the most numerous and diverse neuroglial cells in the $\mathrm{CNS}^{12}$. They are dynamic cells that respond to changes in the CNS by undergoing morphological and functional alterations that affect neuronal activity $^{9,12}$. In response to CNS insults, astrocytes develop a hypertrophic or reactive phenotype termed astrogliosis, which is characterized by the upregulation of specific structural proteins, such as glial fibrillary acidic protein (GFAP) and vimen$\operatorname{tin}^{12,13,14,15}$. Hypothalamic astrogliosis has been widely associated with high-fat diet-induced obesity ${ }^{9,16}$.

Propentofylline (PPF) [3-methyl-1-(5'-oxohexyl)-7propylxanthine] is a xanthine derivative that has demonstrated profound neuroprotective, antiproliferative and antiinflammatory effects in several animal models ${ }^{17}$. Clinically, it has shown efficacy in degenerative vascular dementia ${ }^{18}$ and as a potential adjuvant treatment in Alzheimer's disease ${ }^{19}$, schizophrenia $^{20}$ and multiple sclerosis ${ }^{21}$. It probably depresses activation of microglial cells and astrocytes, which is associated with neuronal damage during inflammation and hypoxia, and consequently decreases glial production and release of damaging proinflammatory factors ${ }^{17}$. It has previously been seen that PPF decreased the peripheral astrogliosis observed following gliotoxic injury in the rat brainstem ${ }^{22}$.

Thus, the objective of the present study was to investigate if PPF could attenuate the hypothalamic astrogliosis induced by a hypercaloric diet (HD) as seen in previous studies.

\section{METHODS}

The animal procedures were performed in accordance with the guidelines of the Committee on Care and Use of Laboratory Animal Resources and Brazilian Institutional Ethics Committee guidelines (University Paulista, protocol number 376/15, CEUA/ICS/UNIP). All efforts were made to minimize animal suffering.

Twenty-four adult male Wistar rats, 12 weeks of age and weighing 300-350 g, were divided into four groups ( $\mathrm{n}=6$ in each): NDS group - rats receiving a normocaloric diet (ND) and treated with $0.9 \%$ saline solution; NDP group - rats receiving the ND and treated with PPF; HDS group - rats receiving a hypercaloric diet (HD) and treated with $0.9 \%$ saline solution, HDP group - rats receiving the HD and treated with PPF.

Upon arrival at our laboratory, rats were housed in microisolator cages (four rats per cage) under controlled temperatures $\left(22-25^{\circ} \mathrm{C}\right)$ and humidity $(50-65 \%)$, in artificially-lit rooms on a 12-hour light-dark cycle (lights on 07:00) and food and water ad libitum.

Rats from the HDS and HDP groups received free access to the HD, which was the highly palatable liquid diet supplement Ensure (Abbott Laboratorios do Brasil, São Paulo, Brazil; total of $\left.1 \mathrm{kcal} \mathrm{mL}^{-1}\right)$. Each 231-kcal bottle contained $1.7 \mathrm{~g}$ polyunsaturated fat, $3.59 \mathrm{~g}$ monounsaturated fat, and
$2.2 \mathrm{~g}$ saturated fat, with no trans fat. It was presented in a graduated cylinder with a stopper, with $600 \mathrm{~mL}$ per bottle. The ND (nutritionally balanced food) was irradiated laboratory chow (Nuvilab; Sogorb Indústria e Comércio, São Paulo, Brazil, with the following values per $100 \mathrm{~g}$ of solid food item: $4.2 \mathrm{kcal} \mathrm{g}^{-1}$, 56\% carbohydrate, $19 \%$ protein, $4.5 \%$ cellulose, $5 \%$ vitamins and $3.5 \%$ g total fat). This was given to all experimental groups, including those receiving the HD. Rats from the HD and ND diet groups were housed four per cage and Ensure and laboratory chow were made available to each cage as a whole. Both diets were replenished daily.

The animals were weighed weekly for 21 days and weight gain was defined as the ratio between the final weight and initial weight.

Rats from the NDP and HDP groups were treated daily with a PPF solution $(20 \mathrm{mg} / \mathrm{ml}$, Agener União Química, São Paulo - SP) by intraperitoneal route using $12.5 \mathrm{mg} / \mathrm{kg} /$ day during the experimental period. Rats from the NDS and HDS groups received $0.9 \%$ saline solution intraperitoneal injections daily.

On the $21^{\text {st }}$ day, the rats were anesthetized (thiopental, $60 \mathrm{mg} / \mathrm{kg}$ intraperitoneally, Thiopentax", Cristália, Itapira, Brazil) and submitted to intracardiac perfusion with $4 \%$ glutaraldehyde in $0.1 \mathrm{M}$ Sorensen phosphate buffer $(\mathrm{pH}$ 7.4). The brains were collected and fixed in $10 \%$ buffered formalin for 72 hours. Coronal sections of each brain were made to reach the periventricular area of the hypothalamus (using the following coordinates $-5.64 \mathrm{~mm}$ from interaural line and $-3.36 \mathrm{~mm}$ from the bregma ${ }^{23}$ ). The tissue was embedded in paraffin for processing for conventional histological procedures. The GFAP immunohistochemistry was performed using the chain polymer-conjugated staining method (Dako EnVision System). We used polyclonal rabbit anti-GFAP immunoglobulin (1:50; Z033401, Dako, Glostrup, Denmark) as the primary antibody followed by the EnVision+ Kit (HRP, Rabbit, DAB+, K4011, Dako, Glostrup, Denmark). Three sections ( $5 \mu \mathrm{m}$ thick) per rat were made and, from each individual section and using a 40x objective, ten photomicrographs of the periventricular hypothalamus were taken. The area of GFAP+ cells and their processes, marked in brown, was automatically calculated, in pixels, using Image-ProPlus 6.0 software (Media Cybernetics, Silver Spring, USA) calibrated with digital color filters such that only positive cells were included and background staining was excluded from the measurement.

Homoscedasticity was verified using the Bartlett's test. Normality was verified using the Kolmogorov-Smirnov test. Two-way ANOVA followed by Tukey's test (for body weight gain) or the Sidak test (for GFAP expression) were used to analyze data with two factors (diets and treatments). Results were expressed as means \pm standard errors of the means. In all cases, results were considered significant at $\mathrm{p}<0.05$. 


\section{RESULTS}

Increased body weight gain by the $21^{\text {st }}$ day was seen in the HDS and HDP groups relative to the NDS and NDP groups $(p<0.0001)$ (Figure 1). As for the hypothalamic GFAP expression, differences between diets $(\mathrm{p}<0.0001)$ and treatments $(\mathrm{p}$ $<0.0001)$ were observed, with interaction between factors ( $p$ $<0.0001)$. The Sidak post-test indicated an increased GFAP expression in the HDS group relative to the other experimental groups (NDS, NDP and HDP) (Figure 2). Propentofylline was able to decrease the astrogliosis induced by the HD in the HDP group, although the expression of GFAP in this group was still greater compared to the NDS and NDP groups $(p<0.01)$.

The expression of GFAP in hypothalamic astrocytes from the different groups are seen in Figure 3.

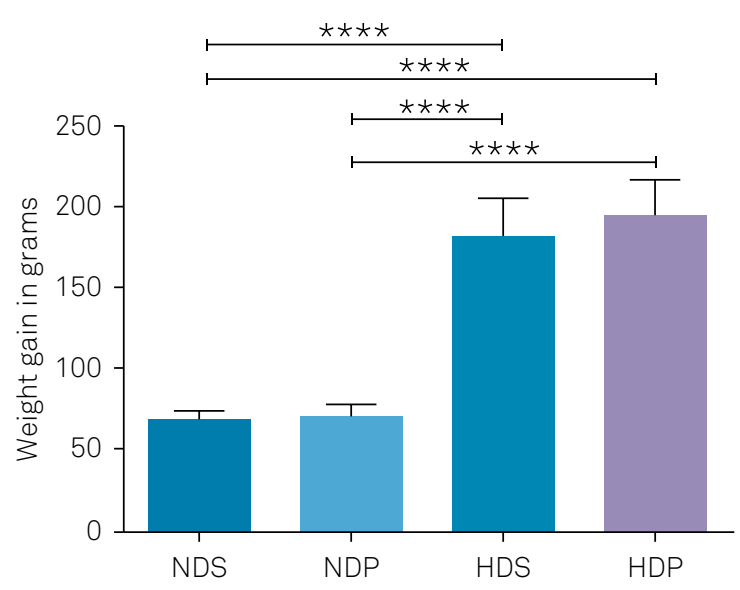

Figure 1. Weight gain (in grams) in 21 days. Groups comprise the NDS (normocaloric diet + saline), NDP (normocaloric diet + propentofylline), HDS (hypercaloric diet + saline) and HDP (hypercaloric diet + propentofylline). Data are expressed as means \pm standard errors of the means. $* * * \star p<0.0001$.

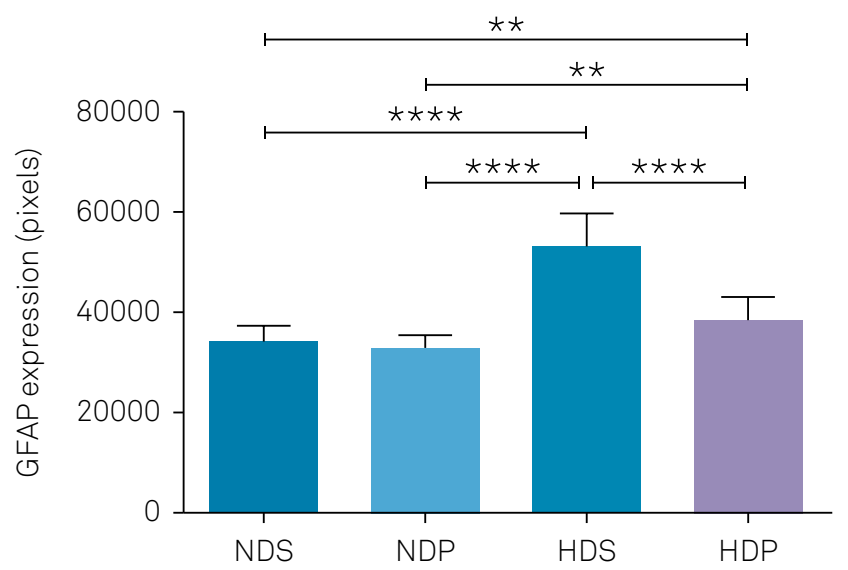

Figure 2. GFAP immunostaining (represented as total count of pixels) in groups comprising the NDS (normocaloric diet + saline), NDP (normocaloric diet + propentofylline), HDS (hypercaloric diet + saline) and HDP (hypercaloric diet + propentofylline). Data are expressed as means \pm standard errors of the means. ${ }^{* *} p<0.01 ; * * * * p<0.0001$.

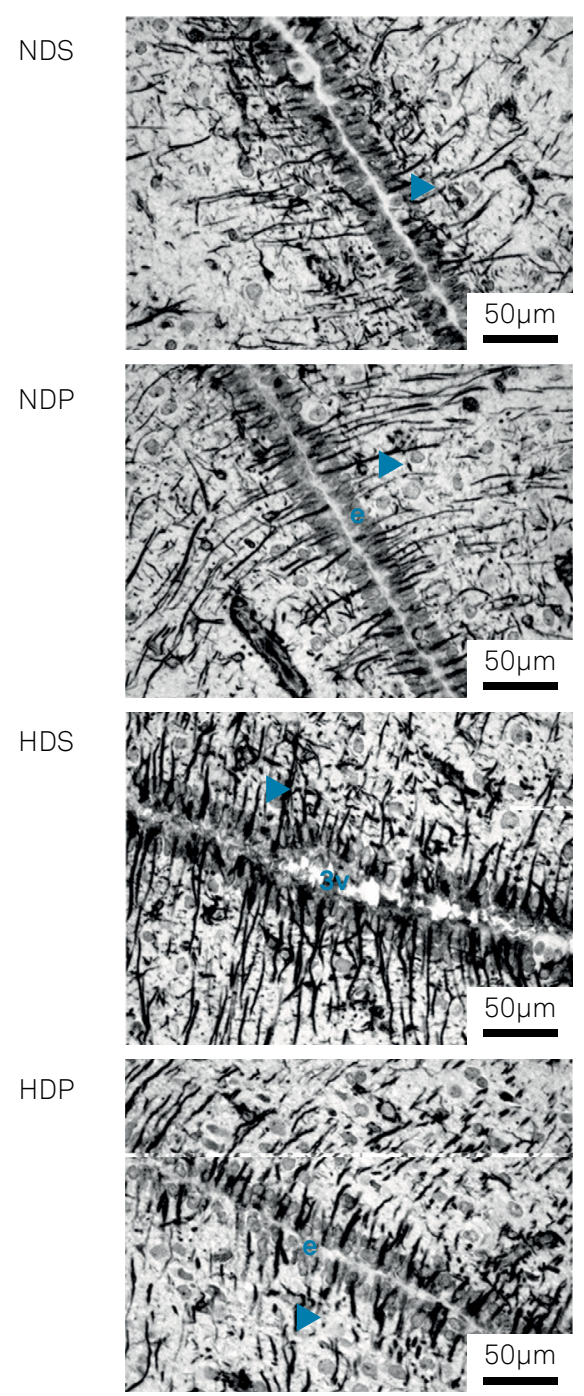

Figure 3. Astrocyte GFAP expression in the periventricular zone of the hypothalamus. Groups comprise the NDS (normocaloric diet + saline), NDP (normocaloric diet + propentofylline), HDS (hypercaloric diet + saline) and HDP (hypercaloric diet + propentofylline). $3 \mathrm{v}$ - third ventricle; $\mathrm{e}$ ependymal cells; arrowheads - astrocyte processes. GFAP immunohistochemistry.

\section{DISCUSSION}

Hypothalamic inflammation may exert a paradoxical effect on energy homeostasis depending on the time course, the involved proinflammatory signals, and the degree of inflammation. An intense acute inflammatory response, as in an infection, induces a state of negative energy balance, although chronic and mild inflammation, as seen in obesity, has the opposite effect ${ }^{9}$. In our study, an inflammatory response was achieved in the hypothalamus, as suggested by the strong increase in the astrocyte expression of GFAP, indicative of intense astrogliosis in response to the HD. The differences in the weight gain seen in rats fed with the ND or HD from the beginning of the experiment until its conclusion 21 days later, confirmed the effect of the HD we used in creating overweight or obese rats. 
Both leptin (an anorexigenic hormone primarily produced by adipose tissue) and ghrelin (the most important orexigenic hormone identified to date) are capable of inducing rapid modifications in synaptic inputs to neurons that secrete the anorexigenic pro-opiomelanocortin and the orexigenic neuropeptide $\mathrm{Y}$ in the arcuate nucleus of the hypothalamus ${ }^{24}$. However, food intake and body weight maintenance depend on the proper functioning of several hypothalamic areas, such as the ventromedial (controlling appetite, body weight and insulin regulation), the lateral complex (appetite and body weight control), the arcuate (feeding and control of anterior pituitary, including GH and TSH secretion), the posterior (thermoregulation), the supraoptic (fluid balance), the suprachiasmatic (biological rhythms), the preoptic and the lateral (lateral anterior thermoregulation) and the paraventricular (fluid balance, anterior pituitary and autonomic control, including regulation of sympathetic induced lipolysis and thermogenesis) $)^{9,10,23}$. Given the complexity of its circuitry we have chosen to consider the whole hypothalamus as a unique structure of special interest in the observation of astrocytic GFAP expression. It would be simplistic to consider only the arcuate nucleus, the ventromedial hypothalamus or the paraventricular nucleus as important centers for controlling feeding and metabolism.

Hypothalamic astrocytes express various types of leptin receptors, indicating direct effects of the hormones on these cells ${ }^{25}$. High-fat intake and obesity are associated with activation of inflammatory signaling pathways in the hypothalamus involving astrocytes and microglia and resulting in leptin and insulin resistance and disturbed control of homeostasis ${ }^{10,24}$. In obesity, increased expression of leptin receptors in hypothalamic astrocytes may suggest the sequestering of leptin by astrocytes thus leading to decreased leptin signaling to neurons ${ }^{26}$.

Astrocytes control both glucose and lipid transport and metabolism in the $\mathrm{CNS}^{24}$. Apolipoprotein E, the most abundant lipid transporter in the CNS, is produced mainly in astrocytes, acting as a satiety factor in the hypothalamus, possibly mediating some of the inhibitory effects of leptin. It is widely known that astrocytes oxidize fatty acids to produce ketone bodies, which constitute an energy source for neurons. On the other hand, ketones mediate leptin and insulin signaling in the hypothalamus thus affecting energy homeostasis ${ }^{24}$.

It remains to be determined if morphological changes in astrocytes and in the number of synaptic inputs to neurons of the arcuate nucleus are a cause or a consequence of the increased weight gain and its complications ${ }^{24}$. Exposure to a high-fat diet was associated with reactive gliosis and this affected the structure of the blood-brain barrier, such that the pro-opiomelanocortin and neuropeptide $\mathrm{Y}$ cell bodies and dendrites became less accessible to blood vessels ${ }^{27}$. It is unclear whether synaptic inputs are first removed and astrocytes respond by taking up the vacant space and/or if they actively remove synapses and occupy new spaces ${ }^{27}$.
The astrogliosis observed in our investigation, due to administration of the HD, is known to be accompanied by increased cytokine expression and attenuation of leptin signaling in the hypothalamic neurons ${ }^{9,16}$. Activated astrocytes may lose their homeostatic functions upon exposure to stressors, decreasing glutamate uptake and increasing the expression of deleterious proinflammatory molecules such as cytokines, nitric oxide, prostaglandins, among others, as an injury response $\mathrm{e}^{12,15}$.

Many different types of signaling molecules, including cytokines, are able to trigger and/or regulate astrogliosis and can be released by all cell types of the CNS tissue, including invasive inflammatory/immune cells, neurons, microglia, oligodendrocyte lineage cells, pericytes, endothelia and other astrocytes ${ }^{12,14}$.

In the CNS, PPF may serve as a glial modulator, with direct actions on microglia, and dose dependently decreases microglial proliferation and expression of inflammatory cytokines, such as TNF- $\alpha$ and IL-1 $\beta$, as seen in response to lipopolysaccharide stimulation in vitro ${ }^{28,29}$.

Known mechanisms of PPF include inhibition of cyclic AMP (cAMP) and cyclic GMP phosphodiesterases, and action as a reuptake inhibitor for the purine nucleoside and neurotransmitter adenosine by blocking the action of membrane nucleoside transporters. This may lead to increased intracellular cAMP levels and greater extracellular concentrations of adenosine, which stimulates adenosinergic neurotransmission and adenosine 2 receptor-mediated cAMP synthesis ${ }^{17}$.

Regulation of cytokine production includes the adenylate cyclase-cAMP-protein kinase pathway ${ }^{29}$. Propentofylline, a type III-IV specific phosphodiesterase inhibitor, although it decreases, in a dose-dependent manner, the production of the inflammatory cytokines TNF- $\alpha$, IL- 1 and IL- 6 by mouse microglia stimulated by lipopolysaccharide in vitro, increases up to two or three times the production of the inhibitory cytokine IL-10, which suppresses cytokine release by microglia and macrophages and attenuates astroglial reactivity in vivo ${ }^{29}$.

A $\mathrm{Ca}^{++}$-dependent and excessive activation of glial cells is usually found in neuroinflammation and, in this context, increased levels of adenosine induced by PPF administration ${ }^{12}$ may perform a regulatory role on these $\mathrm{Ca}^{++}$- and cAMPdependent molecular signaling pathways that determine many cell-related functions, such as cellular proliferation rate, differentiation state, cytokine production, among others. A strengthening of the cAMP signaling, which can be achieved by adenosine agonists and by PPF, stimulates the production of trophic factors in astrocytes, apparently preventing a deleterious and secondary astrocytic activation caused by previous microglial upregulation. Although not entirely understood, it has been accepted that drugs that elevate extracellular adenosine and/or block the degradation of cyclic nucleotides, like $\mathrm{PPF}$, may be used to counteract glia-related damage in CNS pathological processes ${ }^{22,29,30}$.

Thus, morphometric analysis of GFAP expression in the present study unequivocally demonstrated that PPF 
decreased astrocytic activation 21 days after the onset of administration of the HD, probably by simultaneously suppressing the release of proinflammatory molecules, such as the above-mentioned TNF- $\alpha$, IL-1 $\beta$ and IL- 6 , which may trigger and promote astrogliosis during inflammation, and by increasing secretion of the anti-inflammatory cytokine IL-10. In conclusion, our results clearly indicate that PPF may have a role in reducing astrocytic overactivation following hypercaloric or high-fat diets. In turn, PPF did not show any effect on reducing the weight gain induced by the HD.

\section{References}

1. Bruce-Keller AJ, Keller JN, Morrison CD. Obesity and vulnerability of the CNS. Biochim Biophys Acta. 2009 May;1792(5):395-400. https://doi.org/10.1016/j.bbadis.2008.10.004

2. Mueller K, Sacher J, Arelin K, Holiga S, Kratzsch J, Villringer A et al. Overweight and obesity are associated with neuronal injury in the human cerebellum and hippocampus in young adults: a combined MRI, serum marker and gene expression study. Transl Psychiatry. 2012 Dec;2(12):e200. https://doi.org/10.1038/tp.2012.121

3. Ravanan P, Harry GJ, Awada R, Hoareau L, Tallet F, Roche R et al. Exposure to an organometal compound stimulates adipokine and cytokine expression in white adipose tissue. Cytokine. 2011 Mar;53(3):355-62. https://doi.org/10.1016/j.cyto.2010.11.015

4. Ho AJ, Raji CA, Becker JT, Lopez OL, Kuller LH, Hua Xet al. Obesity is linked with lower brain volume in $700 \mathrm{AD}$ and MCl patients. Neurobiol Aging. 2010 Aug;31(8):1326-39. https://doi.org/10.1016/j.neurobiolaging.2010.04.006

5. Kullmann S, Schweizer F, Veit R, Fritsche A, Preissl H. Compromised white matter integrity in obesity. Obes Rev. 2015 Apr;16(4):273-81. https://doi.org/10.1111/obr.12248

6. García-Ptacek S, Faxén-Irving G, Cermáková P, Eriksdotter M, Religa D. Body mass index in dementia. Eur J Clin Nutr. 2014 Nov;68(11):1204-9. https://doi.org/10.1038/ejcn.2014.199

7. Praticò D, Trojanowski JQ. Inflammatory hypotheses: novel mechanisms of Alzheimer's neurodegeneration and new therapeutic targets? Neurobiol Aging. 2000 May-Jun;21(3):441-5. https://doi.org/10.1016/S0197-4580(00)00141-X

8. Golden TR, Hinerfeld DA, Melov S. Oxidative stress and aging: beyond correlation. Aging Cell. 2002 Dec;1(2):117-23. https://doi.org/10.1046/j.1474-9728.2002.00015.x

9. García-Cáceres C, Yi CX, Tschöp MH. Hypothalamic astrocytes in obesity. Endocrinol Metab Clin North Am. 2013 Mar;42(1):57-66. https://doi.org/10.1016/j.ecl.2012.11.003

10. Thaler JP, Yi CX, Schur EA, Guyenet SJ, Hwang BH, Dietrich $\mathrm{MO}$ et al. Obesity is associated with hypothalamic injury in rodents and humans. J Clin Invest. 2012 Jan;122(1):153-62. https://doi.org/10.1172/JCl59660

11. Becskei C, Riediger T, Hernádfalvy N, Arsenijevic D, Lutz TA, Langhans W. Inhibitory effects of lipopolysaccharide on hypothalamic nuclei implicated in the control of food intake. Brain Behav Immun. 2008 Jan;22(1):56-64. https://doi.org/10.1016/j.bbi.2007.06.002

12. Sofroniew MV, Vinters HV. Astrocytes: biology and pathology. Acta Neuropathol. 2010;119:7-35. https://doi.org/10.1007/s00401-009-0619-8

13. Pekny M, Pekna M. Astrocyte intermediate filaments in CNS pathologies and regeneration. J Pathol. 2004 Nov;204(4):428-37. https://doi.org/10.1002/path.1645

14. Sofroniew MV. Molecular dissection of reactive astrogliosis and glial scar formation. Trends Neurosci. 2009 Dec;32(12):638-47. https://doi.org/10.1016/j.tins.2009.08.002

15. Cregg JM, DePaul MA, Filous AR, Lang BT, Tran A, Silver J. Functional regeneration beyond the glial scar. Exp Neurol. 2014 Mar;253:197207. https://doi.org/10.1016/j.expneurol.2013.12.024

16. Buckman LB, Thompson MM, Moreno HN, Ellacott KL. Regional astrogliosis in the mouse hypothalamus in response to obesity.J Comp Neurol. 2013 Apr;521(6):1322-33. https://doi.org/10.1002/cne.23233
17. Sweitzer S, De Leo J. Propentofylline: glial modulation, neuroprotection, and alleviation of chronic pain. Handb Exp Pharmacol. 2011;200(200):235-50. https://doi.org/10.1007/978-3-642-13443-2_8

18. Kittner B, Rössner M, Rother M. Clinical trials in dementia with propentofylline. Ann NYAcad Sci. 1997 Sep;826 Cerebrovascul:307-16. https://doi.org/10.1111/j.1749-6632.1997.tb48481.x

19. Bachynsky J, McCracken P, Lier D, Alloul K, Jacobs P. Propentofylline treatment for Alzheimer disease and vascular dementia: an economic evaluation based on functional abilities. Alzheimer Dis Assoc Disord. 2000 Apr-Jun;14(2):102-11. https://doi.org/10.1097/00002093-200004000-00008

20. Salimi S, Fotouhi A, Ghoreishi A, Derakhshan MK, Khodaie-Ardakani MR, Mohammadi MR et al. A placebo controlled study of the propentofylline added to risperidone in chronic schizophrenia. Prog Neuropsychopharmacol Biol Psychiatry. 2008 Apr;32(3):726-32. https://doi.org/10.1016/j.pnpbp.2007.11.021

21. Suzumura A, Nakamuro T, Tamaru T, Takayanagi T. Drop in relapse rate of MS by combination therapy of three different phosphodiesterase inhibitors. Mult Scler. 2000 Feb;6(1):56-8. https://doi.org/10.1177/135245850000600111

22. Bondan EF, Martins MF, Dossa PD, Viebig LB, Cardoso CV, Martins $\mathrm{JL}$ et al. Propentofylline reduces glial scar development following gliotoxic damage in the rat brainstem. Arq Neuropsiquiatr. 2016 Sep;74(9):730-6. https://doi.org/10.1590/0004-282X20160108

23. Paxinos \& Watson. The rat brain in stereotaxic coordinates. 5 th ed. San Diego: Elsevier; 2005.

24. Chowen JA, Argente J, Horvath TL. Uncovering novel roles of nonneuronal cells in body weight homeostasis and obesity. Endocrinology. 2013 Sep;154(9):3001-7. https://doi.org/10.1210/en.2013-1303

25. Hsuchou H, He Y, Kastin AJ, Tu H, Markadakis EN, Rogers RC et al. Obesity induces functional astrocytic leptin receptors in hypothalamus. Brain. 2009 Apr;132(Pt 4):889-902. https://doi.org/10.1093/brain/awp029

26. Pan W, Hsuchou H, Xu C, Wu X, Bouret SG, Kastin AJ. Astrocytes modulate distribution and neuronal signaling of leptin in the hypothalamus of obese A vy mice. J Mol Neurosci. 2011 Mar;43(3):478-84. https://doi.org/10.1007/s12031-010-9470-6

27. Horvath TL, Sarman B, García-Cáceres C, Enriori PJ, Sotonyi P, Shanabrough $\mathrm{M}$ et al. Synaptic input organization of the melanocortin system predicts diet-induced hypothalamic reactive gliosis and obesity. Proc Natl Acad Sci USA. 2010 Aug;107(33):14875-80. https://doi.org/10.1073/pnas.1004282107

28. Si Q, Nakamura Y, Ogata T, Kataoka K, Schubert P. Differential regulation of microglial activation by propentofylline via cAMP signaling. Brain Res. 1998 Nov;812(1-2):97-104. https://doi.org/10.1016/S0006-8993(98)00954-8

29. Yoshikawa M, Suzumura A, Tamaru T, Takayanagi T, Sawada M. Effects of phosphodiesterase inhibitors on cytokine production by microglia. Mult Scler. 1999 Apr;5(2):126-33. https://doi.org/10.1177/135245859900500210

30. Schubert P, Morino T, Miyazaki H, Ogata T, Nakamura Y, Marchini $C$ et al. Cascading glia reactions: a common pathomechanism and its differentiated control by cyclic nucleotide signaling. Ann N Y Acad Sci. 2000 Apr;903 1 VASCULAR FACT:24-33. https://doi.org/10.1111/j.1749-6632.2000.tb06346.x 